\title{
Review
}

Neuro

epidemiology

\section{Aging and the Epidemiology of Epilepsy}

\author{
Ettore Beghi Giorgia Giussani \\ Department of Neuroscience, Istituto di Ricerche Farmacologiche Mario Negri IRCCS, Milan, Italy
}

\section{Keywords}

Epilepsy · Epidemiology · Elderly · Dementia · Stroke · Aging

\begin{abstract}
Background: Epilepsy is a chronic disorder affecting all ages but with a peak in the elderly. The association of epilepsy with age can be explained by the predominance of brain diseases with epileptogenic potential (mostly stroke and dementia) and by the effects of the aging process through a number of molecular mechanisms involving networks of neurons with focal or diffuse distribution. Summary: The prevalence of active epilepsy is 6.4 per 1,000 and the lifetime prevalence is 7.6 per 1,000 . The prevalence tends to increase with age, with peaks in the oldest age groups and in socially deprived individuals. The incidence of epilepsy is 61.4 per 100,000 person-years. Epilepsy has a bimodal distribution according to age with peaks in the youngest individuals and in the elderly. The increased incidence of seizures and epilepsy in the elderly can be attributed to the increase of age-
\end{abstract}

related and aging-related epileptogenic conditions. Key Messages: As the world population is steadily growing with parallel increase in the number of aged subjects, in the future, epilepsy will represent a huge burden for the society. Measures must thus be taken to prevent seizures and epilepsy through the reduction of preventable epileptogenic factors.

(c) 2018 S. Karger AG, Basel

Epilepsy is a chronic disorder of the brain characterized by recurrent episodic attacks, epileptic seizures, and their somatic and psychiatric consequences. Seizures are the clinical manifestations of a process involving networks of neurons with focal or diffuse distribution. The development of seizures correlates with age not only because several epileptogenic conditions are age- or agingrelated but also because the aging process in itself can be a risk factor for seizures. For these reasons, the persisting increase and the progressive aging of the world population with time can be associated with an increase in the frequency of epilepsy.

\section{KARGER}

(c) 2018 S. Karger AG, Basel

E-Mail karger@karger.com

www.karger.com/ned
Ettore Beghi, MD

Laboratory of Neurological Disorders

IRCCS-Istituto di Ricerche Farmacologiche "Mario Negri"

Via Giuseppe La Masa 19, IT-20156 Milan (Italy)

E-Mail ettore.beghi@ marionegri.it 


\section{The Changing Definitions of Seizures and Epilepsy and Reflections for the Elderly}

The most recent definition of epilepsy [1] has profound reflections for the burden of the disease in the elderly. According to the International League Against Epilepsy, epilepsy can be diagnosed not only at the presence of 2 or more unprovoked seizures, as in the past [2], but also in patients with one unprovoked (or reflex) seizure and a probability of further seizures similar to the general recurrence risk (at least 60\%) after 2 unprovoked seizures, occurring over the next 10 years [1]. In addition to unprovoked seizures, elderly patients may experience acute symptomatic seizures, that is, seizures occurring in close temporal association with a documented metabolic or structural brain insult [3]. In view of the frequent occurrence of acute symptomatic seizures and single unprovoked seizures in several clinical conditions in the same population [4-6], the inclusion of these seizures in epidemiological surveys will result in a significant increase in the burden of epilepsy when comparing the most recent studies to the old epidemiological reports.

\section{Mechanisms Underlying Aging and Epilepsy}

Several mechanisms are implicated to explain the association between aging and epilepsy. The $\mathrm{Na}+/ \mathrm{K}+$ pump or sodium- and potassium-activated adenosine $5^{\prime}$-triphosphatase ( $\mathrm{Na}+, \mathrm{K}+-\mathrm{ATPase})$ is involved in signaling pathways, enzyme changes during aging and in diverse neurological and psychiatric diseases, including stroke, traumatic brain injury, depression and other mood disorders, mania, Alzheimer's disease (AD), and learning and cognitive impairment [7]. Oxidative and nitrosative stress are also regarded as possible mechanisms in the pathogenesis of epilepsy [8]. Production of free radicals has a role in the regulation of biological functions, damage to cell structures, and in the pathogenesis of neurodegenerative diseases, such as Parkinson's disease, stroke, and dementia. Studies suggest that patients with neurodegenerative diseases may develop epilepsy with time. Oxidative stress may play a role in the initiation and progression of epilepsy [9]. Abnormally prolonged exposure to glutamate causes excitotoxicity with neuronal injury, that has been implicated in many acute and chronic diseases including ischemic stroke, epilepsy, amyotrophic lateral sclerosis, Alzheimer's, Huntington's, and Parkinson's disease [10]. Glutamate excitotoxicity increases oxidative stress in both in vitro and in vivo models, and accumulat- ing evidence indicates that glutamate-induced oxidative stress contributes to neuronal death in neurodegenerative diseases [11]. Mitochondrial oxidative stress is a leading mechanism of age-related and aging-related degenerative diseases, suggesting an involvement of mitochondrial dysfunction in seizure generation [12]. Mitochondria have critical cellular functions that influence neuronal excitability including production of adenosine triphosphate, fatty acid oxidation, control of apoptosis and necrosis, regulation of amino acid cycling, neurotransmitter biosynthesis, and regulation of cytosolic $\mathrm{Ca}(2+)$ homeostasis. Vascular, inflammatory and metabolic factors can be also implicated in the aging process and can explain cognitive dysfunction in people with epilepsy [13]. All these mechanisms make it difficult to understand whether the association between epilepsy and aging is direct or mediated by other clinical conditions sharing with epilepsy common pathophysiologic abnormalities.

\section{Prevalence of Seizures and Epilepsy in the Elderly}

Epilepsy is quite a common disease in the elderly and is comparatively more frequent in this population compared to children and adults (Fig. 1). The lifetime prevalence of the disease in the general population ranges from 2.3 to 15.9 per 1,000 in high-income countries and from 3.6 to 15.4 per 1,000 in low-income countries [14]. Differences can be explained in part by the differing populations at risk and by differences in case ascertainment methods. The pooled point prevalence ratio of active epilepsy, defined by treatment with antiepileptic drugs or the presence of at least one seizure in the preceding 2-5 years regardless of treatment [15], is 6.4 per 1,000 (95\% CI 5.6-7.3) and the lifetime prevalence is 7.6 per 1,000 (95\% CI 6.2-9.4) [16]. The prevalence of the disease tends to increase with age, with a peak at 20-29 years and a subsequent decrease, with a ratio of 7.17 (95\% CI 4.6711.01 ) in individuals aged 60 years or older. Higher rates can be found when the prevalence is calculated in the context of a prospective survey. In the Rotterdam study that included individuals aged 55 years or older, the overall prevalence of active epilepsy was 9 per 1,000, with an increase with age from 7 per 1,000 for people aged 5564 years to 12 per 1,000 for those aged $85-94$ years [17]. Prevalence ratios can be even higher in racial minorities. Among subjects residing in the US Navajo Reservation who had at least 1 medical encounter, the overall prevalence of epilepsy or seizures was 18.1 per 1,000 and was up to 31.6 and 25.7 per 1,000 among men and women 


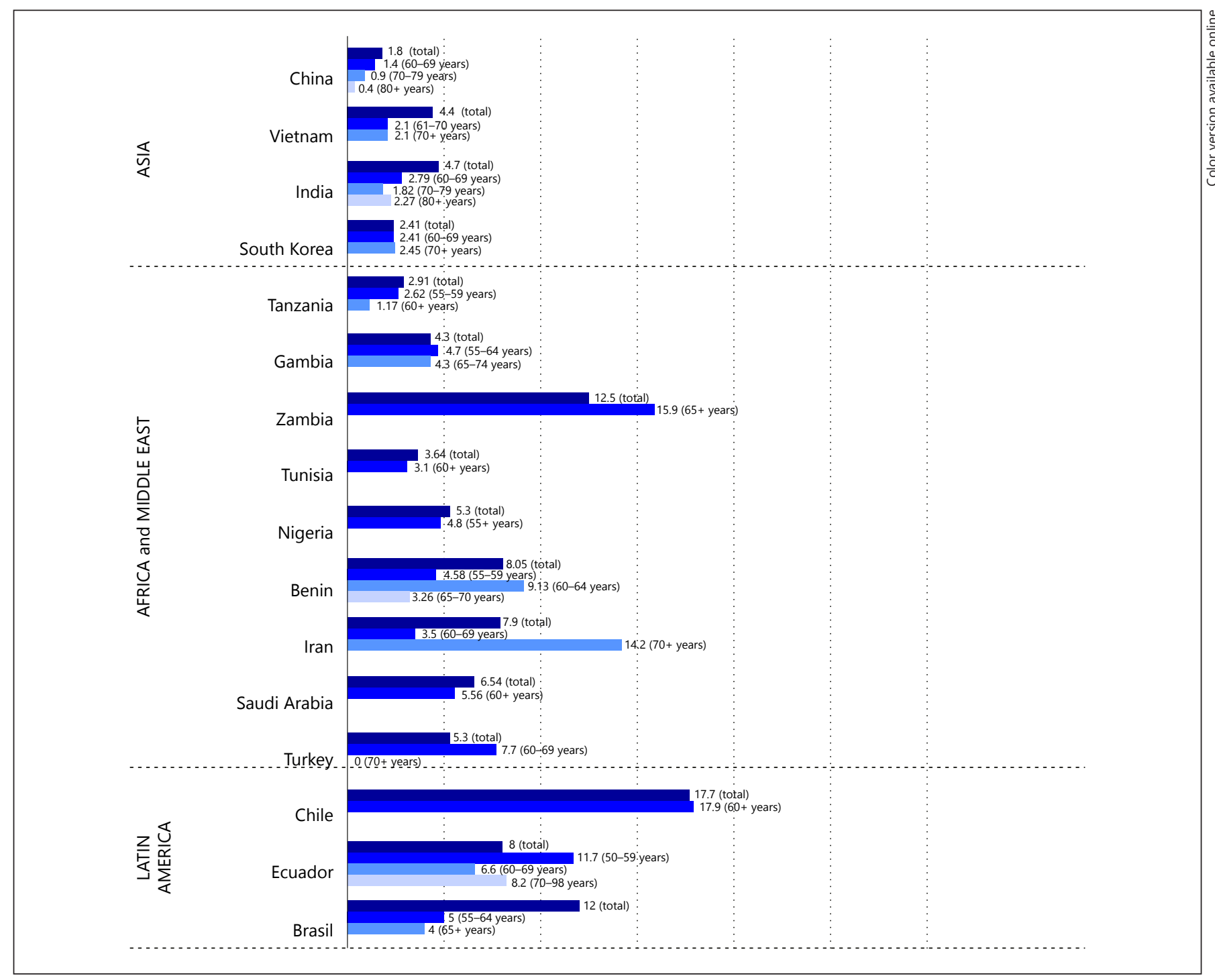

Fig. 1. Prevalence of epilepsy (per 1,000) in various countries, overall and in selected age groups in the elderly. The source references are available upon request to the corresponding author.

(For figure 1 continue next page.)

aged 75 years or older [18]. These findings were explained by the high prevalence of environmental risk factors like traumatic brain injury and alcoholism in this population. Even in nursing home residents, a high-risk population, the prevalence of epilepsy can exceed 5\% [19].

\section{Incidence of Seizures and Epilepsy in the Elderly}

The annual incidence of unprovoked seizures ranges from 33 to 198 per 100,000 and the annual incidence of epilepsy from 24 to 190 per 100,000 [20]. The incidence in high-income countries ranges from 24 to 71.0 per 100,000 per year, while in low/middle-income countries, the incidence is higher and can be up to 190 per 100,000 (Fig. 2). Epilepsy has a bimodal distribution according to age with peaks in the youngest individuals and in the elderly. The increased incidence in the elderly can be attributed to the increase of age-related and aging-related epileptogenic conditions. The pooled incidence rate of epilepsy is 61.4 per 100,000 person-years (95\% CI 50.7-74.4) [16]. The incidence of acute symptomatic seizures also increases with advancing age [4]. This is particularly true for status epilepticus. Acute symptomatic status epilepticus accounts for most etiologies across all age groups [21], but the causes vary according to age, with stroke, traumatic 


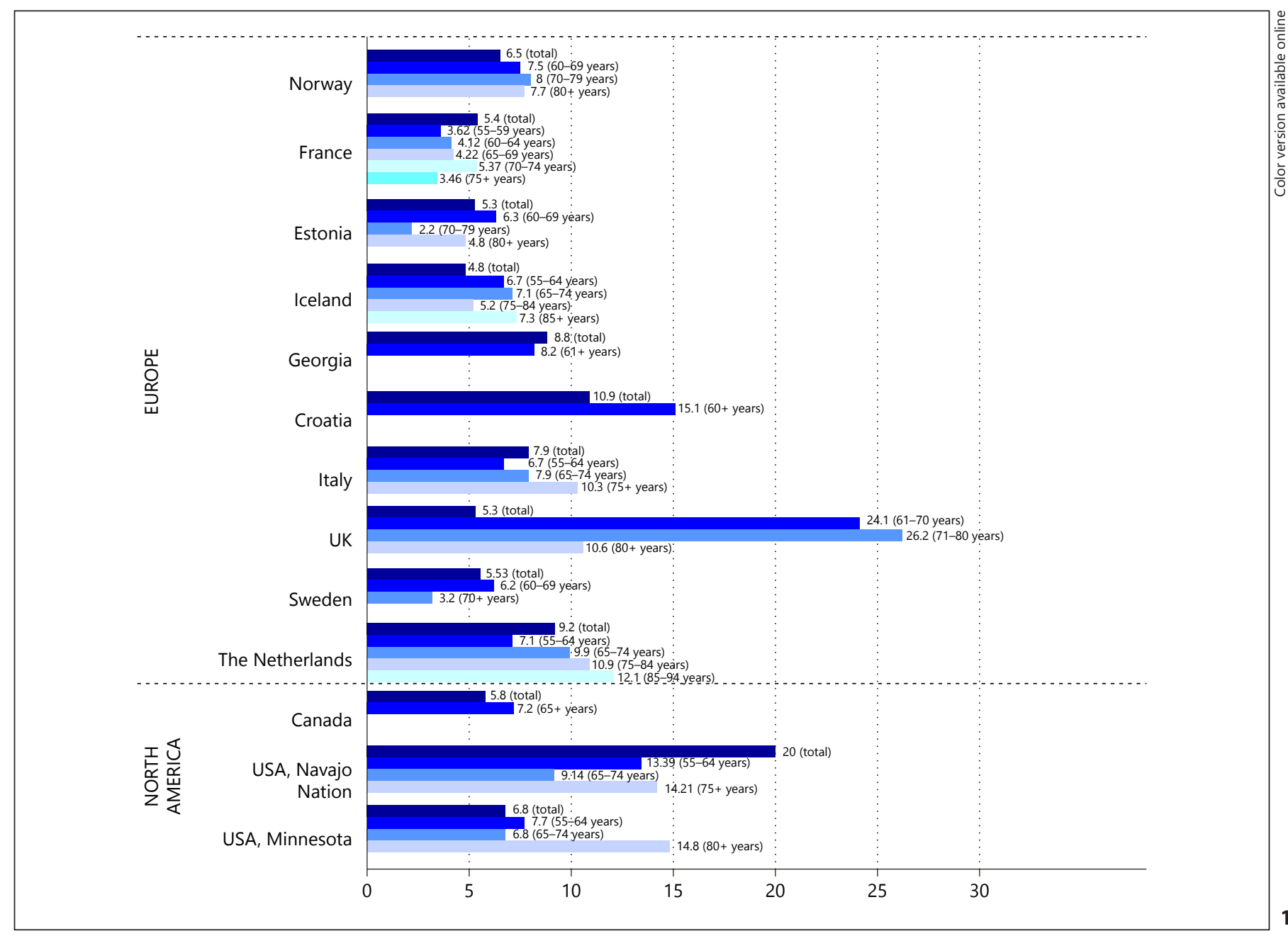

brain injury, and metabolic disorders predominating, in decreasing order, in the elderly [4]. In the Rochester, Minnesota population, the cumulative incidence of epilepsy through age 74 years was 3.0\%, of all unprovoked seizures was $4.1 \%$, and of any convulsive disorder (including acute symptomatic seizures) approached 10\% [22].

\section{Mortality of Seizures and Epilepsy in the Elderly}

The mortality of epilepsy is largely explained by the mortality of the underlying clinical conditions. Although consistently higher standardized mortality ratios (SMRs) are reported in all age groups, comparatively lower SMR elevations are reported in age groups older than 64 years (range 1.4-2.6) [23]. The decreasing mortality of epilepsy in the oldest ages can be explained by the competitive role of other clinical conditions leading to death in aged indi- viduals. Highest SMRs in the youngest age groups were also found in low-income countries, with a continuing decline with increasing age [24]. However, in these countries, data were insufficient to characterize the risk of mortality by age of epilepsy onset. The mortality associated with acute symptomatic seizures is significantly greater in aged populations than in younger age groups [25] and can be mostly explained by the predominance of seizures occurring in close temporal association with stroke.

\section{Temporal Trends}

In the Rochester, Minnesota population, the incidence of epilepsy in the elderly has increased with time, mostly in the last decade of the observation period (up to 253.2 per 100,000) [6]. The increased incidence in the elderly in the US population was consistent with a study in Finland 


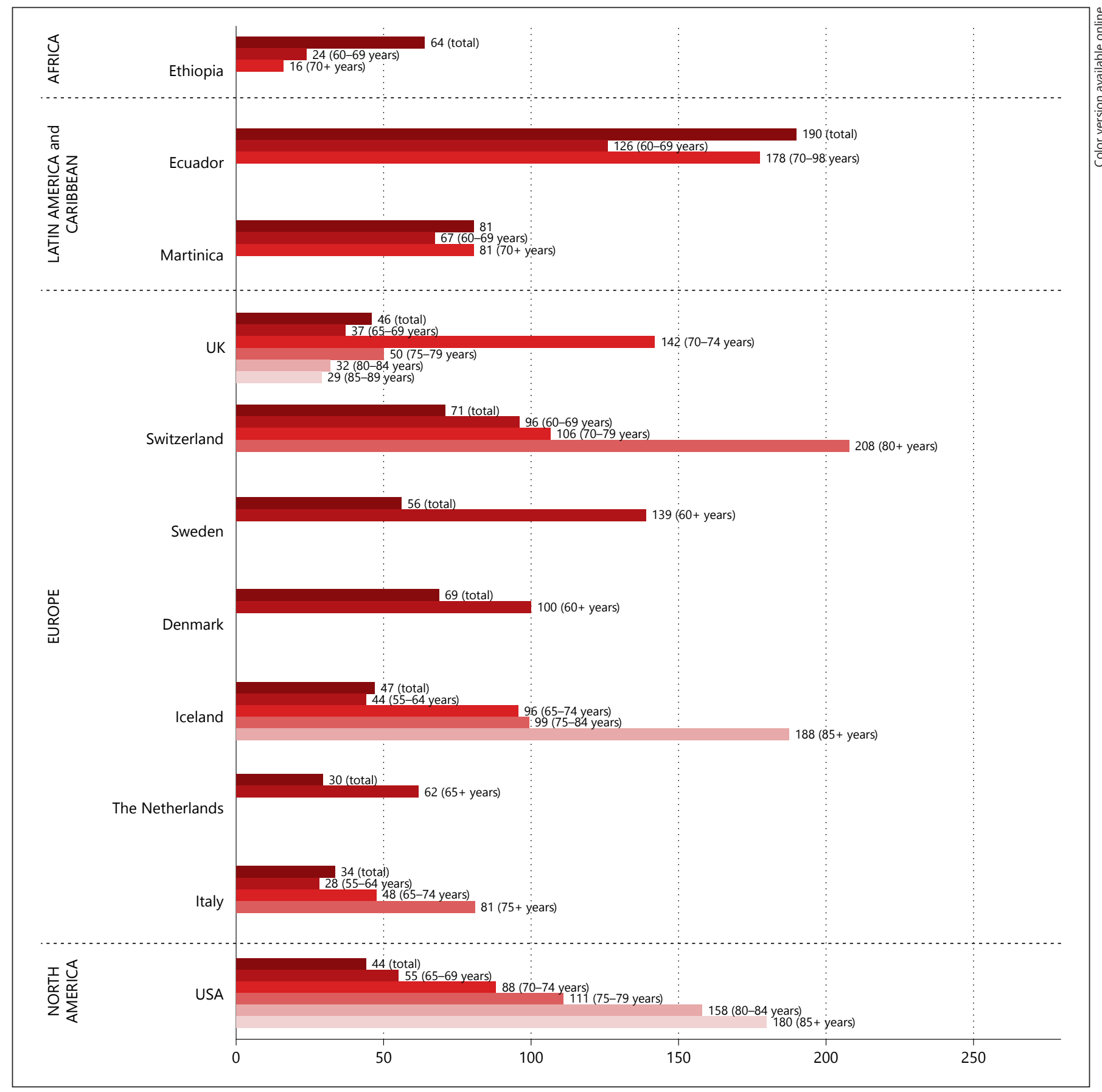

Fig. 2. Incidence of epilepsy (per 100,000/years) in various countries, overall and in selected age groups in the elderly. The source references are available upon request to the corresponding author.

[26]. These findings can be explained by increased life expectancy and better case ascertainment in this age group. In contrast, in a UK population of 6,000 persons followed for 10 years [27], the lifetime prevalence of 1 or more afebrile seizures was 20.3 per 1,000 in 1983 and 21.0 per
1,000 in 1993, but the prevalence of active epilepsy was highest in the elderly (6.1 per 1,000 in patients 60 years or older) and decreased from 5.3 to 4.3 per 1,000 , with no remarkable changes during the study period. Regardless of whether or not age-specific incidence and prevalence 
of epilepsy in the elderly is increasing, the growth of the world population associated with the introduction of more effective preventive measures against communicable diseases in low-income countries will be followed by decreased premature mortality and, consequently, by an increase of the burden of epilepsy in aged individuals.

\section{Global Burden of Disease}

Neurological disorders, including epilepsy, have been found as the leading causes of disability-adjusted life years (DALYs), a measure of the global burden of disease [28]. From the global perspective, epilepsy accounted for about 125,000 deaths, more than 23 million prevalent cases, and more than 12 million DALYs in 2015. Rates varied across countries, with peaks in eastern, southern and central Sub-Saharan Africa and central Asia. The largest burden, as measured by DALYs, has been documented in children and young adults because in the elderly, the burden was generally attributed to stroke and other underlying diseases or injuries causing seizures in this age group.

\section{Clinical Conditions Associated With Increased Risk of Seizures in the Elderly}

Aged individuals are exposed to an increasing number of risk factors for seizures and epilepsy because they experience comorbidities more frequently than children and adults. A number of age-related and aging-related diseases are associated with seizures. These include, among others, $\mathrm{AD}$ and other dementias, stroke and other vascular diseases, and a number of metabolic disorders (mostly diabetes and electrolyte disturbances). All these clinical conditions can present with acute symptomatic and unprovoked seizures. Since a bidirectional association between epilepsy, cerebrovascular and neurodegenerative disorders has been frequently observed [29], there is a possibility that epilepsy in the elderly carries a higher than expected risk of brain injuries of vascular and/or degenerative origin. Genetic mutations and shared risk factors are possible explanations.

\section{Epilepsy, AD, and Other Dementias}

Patients with $\mathrm{AD}$ are at increased risk of seizures and epilepsy [30]. Neurodegeneration in mild cognitive impairment or $\mathrm{AD}$ begins several years earlier in patients with seizures compared to those who do not develop epilepsy [31]. The same is true for patients with AD with subclinical EEG epileptiform activity, even in the absence of seizures [32]. The reported prevalence and incidence of seizures in patients with $\mathrm{AD}$ varies across studies, with lifetime prevalence ranging from 1.5 to $64 \%$ [30]. Compared to non-demented individuals matched for age and sex, patients with $\mathrm{AD}$ have a sixfold risk of unprovoked seizures and people with other types of dementia have even an eightfold risk [33]. In the United Kingdom, the prevalence ratio of $\mathrm{AD}$ in people with and without epilepsy was 8.0 [34]. The cumulative incidence of unprovoked seizures was $7.7 \%$ in a cohort of patients with mild $\mathrm{AD}$ by 7 years of follow-up [31]. Most seizure types in $\mathrm{AD}$ are focal with impaired awareness but myoclonic jerks are not uncommon [35]. Seizures lower the pathologic threshold for the development of cognitive impairment and early dementia in AD. Seizures also contribute to cognitive decline in the earliest stages of AD progression [36]. However, the underlying mechanisms remain to be determined.

\section{Epilepsy and Stroke}

Both ischemic and hemorrhagic stroke are associated with a high risk of seizures and epilepsy. In patients with ischemic stroke, the cumulative incidence is $2-33 \%$ for acute symptomatic seizures, 3-67\% for unprovoked seizures, and 2-4\% for recurrent unprovoked seizures [37]. Focal seizures are of the predominating type. Todd's paresis can be occasionally seen, making the correct differentiation with transient ischemic attacks sometimes difficult. Cortical site, severity, and size of the lesion are independent predictors of acute symptomatic seizures. In a US population-based study, acute symptomatic seizures occurred in $6 \%$ of patients with ischemic stroke [38]. Cerebral infarcts were more likely located in the anterior hemisphere (OR 4.0; 95\% CI 1.2-13.7). There was an inverse correlation between age and risk of seizures with a peak in patients aged less than 55 years. The risks were higher after recurrent stroke. Compared to ischemic stroke, hemorrhagic stroke (subarachnoid hemorrhage and, to a lesser extent, primary intracerebral hemorrhage) are followed by a higher risk of seizures. In the Oxfordshire community stroke project, the cumulative probability of seizures after a first stroke was about $6 \%$ at 1 year and rose to $11 \%$ at 5 years, with significant differences across stroke subtypes (cerebral infarction 4 and 10\%; primary cerebral hemorrhage 20 and $26 \%$; subarachnoid hemorrhage 22 and 34\%) [39]. Acute symptomatic sei- 
zures (onset seizures) occurred in $2.1 \%$ of cases during the first 24 hours. The onset of seizures in late life has also been associated with a significant increase in the risk of stroke suggesting that epilepsy can be a predictor of subsequent stroke [40].

\section{Prognosis of Epilepsy in the Elderly}

Epilepsy is a self-remitting clinical condition in several patients. Among people with newly diagnosed epilepsy followed for several decades, up to $80 \%$ enter prolonged periods of seizure remission and up to $50 \%$ continue to be seizure-free after treatment discontinuation [41, 42]. Clinical experience dictates that the outcome of the disease can be even better in the elderly [43]. In a populationbased cohort of newly diagnosed patients, half of them followed for at least 10 years, the cumulative probability of starting a 2-year sustained seizure remission increased with age and was $90.2 \%$ in individuals aged 55 years or older [44]. However, when other prognostic predictors are taken into consideration, there is no evidence that age at onset of seizures affects seizure outcome [45]. Thus, there is a possibility that patients with acute symptomatic seizures are included, which, by definition, carry a lower risk of relapse than unprovoked seizures [46].

\section{Future Directions}

Future epidemiological studies will show a steady increase in the number of subjects experiencing seizures and epilepsy, with a peak in the elderly. This increase will be explained only in part by the changes in the definition of the disease because the growth of the world population and the overall reduction of premature mortality in lowincome countries will be followed by an increase in the number of surviving aged individuals. This will reflect in a substantial increase of seizures and epilepsy in this age group as a result of the increase in the number of agerelated and aging-related diseases having epileptogenic potential. As the incidence of the disease is highest in the elderly, in low-income countries and in socially deprived minorities, poor aged individuals represent the category at highest risk of seizures and epilepsy. For these reasons, aged subjects require special attention for the detection of the disease and its prevention through the reduction of preventable epileptogenic factors.

\section{Disclosure Statement}

E.B.: reports of having received grants from UCB-Pharma and from the Italian Ministry of Health. G.G. declares no conflicts of interest to disclose.

\section{References}

1 Fisher RS, Acevedo C, Arzimanoglou A, Bogacz A, Cross JH, Elger CE, Engel J Jr, Forsgren L, French JA, Glynn M, Hesdorffer DC, Lee BI, Mathern GW, Moshé SL, Perucca E, Scheffer IE, Tomson T, Watanabe M, Wiebe S: ILAE official report: a practical clinical definition of epilepsy. Epilepsia 2014;55:475-482.

2 Guidelines for epidemiologic studies on epilepsy. Commission on Epidemiology and Prognosis, International League Against Epilepsy. Epilepsia 1993;34:592-596.

3 Beghi E, Carpio A, Forsgren L, Hesdorffer DC, Malmgren K, Sander JW, Tomson T, Hauser WA: Recommendation for a definition of acute symptomatic seizure. Epilepsia 2010;51:671-675.

4 Annegers JF, Hauser WA, Lee JR, Rocca WA. Incidence of acute symptomatic seizures in Rochester, Minnesota, 1935-1984. Epilepsia 1995;36:327-333.

5 Hauser WA, Hesdorffer DC: Genetics; in Hauser WA, Hesdorffer DC (eds): Epilepsy: Frequency, Causes and Consequences. New York, Demos Publications, 1990, pp 93-118.

6 Hauser WA, Annegers JF, Kurland LT: Incidence of epilepsy and unprovoked seizures in
Rochester, Minnesota: 1935-1984. Epilepsia 1993;34:453-468.

7 de Lores Arnaiz GR, Ordieres MG: Brain $\mathrm{Na}(+), \mathrm{K}(+)$-ATPase activity in aging and disease. Int J Biomed Sci 2014;10:85-102.

8 Aguiar $\mathrm{CC}$, Almeida $\mathrm{AB}$, Araújo PV, de Abreu RN, Chaves EM, do Vale OC, Macêdo DS, Woods DJ, Fonteles MM, Vasconcelos SM: Oxidative stress and epilepsy: literature review. Oxid Med Cell Longev 2012;2012: 795259.

9 Costello DJ, Delanty N: Oxidative injury in epilepsy: potential for antioxidant therapy? Expert Rev Neurother 2004;4:541-553.

10 Yang JL, Sykora P, Wilson DM 3rd, Mattson MP, Bohr VA: The excitatory neurotransmitter glutamate stimulates DNA repair to increase neuronal resiliency. Mech Ageing Dev 2011;132:405-411.

11 Mattson MP: Excitotoxic and excitoprotective mechanisms: abundant targets for the prevention and treatment of neurodegenerative disorders. Neuromolecular Med 2003;3:65-94.

12 Waldbaum S, Patel M: Mitochondria, oxidative stress, and temporal lobe epilepsy. Epilepsy Res 2010;88:23-45.
13 Hermann BP, Sager MA, Koscik RL, Young K, Nakamura K: Vascular, inflammatory, and metabolic factors associated with cognition in aging persons with chronic epilepsy. Epilepsia 2017;58:e152e156.

14 Bell GS, Neligan A, Sander JW: An unknown quantity - the worldwide prevalence of epilepsy. Epilepsia 2014;55:958-962.

15 Thurman DJ, Beghi E, Begley CE, Berg AT, Buchhalter JR, Ding D, Hesdorffer DC, Hauser WA, Kazis L, Kobau R, Kroner B, Labiner D, Liow K, Logroscino G, Medina MT, Newton CR, Parko K, Paschal A, Preux PM, Sander JW, Selassie A, Theodore W, Tomson T, Wiebe S; ILAE Commission on Epidemiology: Standards for epidemiologic studies and surveillance of epilepsy. Epilepsia 2011;52(suppl 7): $2-26$.

16 Fiest KM, Sauro KM, Wiebe S, Patten SB, Kwon CS, Dykeman J, Pringsheim T, Lorenzetti DL, Jetté N: Prevalence and incidence of epilepsy: a systematic review and meta-analysis of international studies. Neurology 2017; 88:296-303. 
17 de la Court A, Breteler MM, Meinardi H, Hauser WA, Hofman A: Prevalence of epilepsy in the elderly: the Rotterdam Study. Epilepsia 1996;37:141-147.

18 Parko K, Thurman DJ: Prevalence of epilepsy and seizures in the Navajo Nation 1998-2002. Epilepsia 2009;50:2180-2185.

19 Schachter SC, Cramer GW, Thompson GD, Chaponis RJ, Mendelson MA, Lawhorne L: An evaluation of antiepileptic drug therapy in nursing facilities. J Am Geriatr Soc 1998;46: 1137-1141.

20 Kotsopoulos IA, van Merode T, Kessels FG, de Krom MC, Knottnerus JA: Systematic review and meta-analysis of incidence studies of epilepsy and unprovoked seizures. Epilepsia 2002;43:1402-1409.

21 Chin RF, Neville BG, Scott RC: A systematic review of the epidemiology of status epilepticus. Eur J Neurol 2004;11:800-810.

22 Hauser WA, Annegers JF, Rocca WA: Descriptive epidemiology of epilepsy: contributions of population-based studies from Rochester, Minnesota. Mayo Clin Proc 1996;71: 576-586.

23 Thurman DJ, Logroscino G, Beghi E, Hauser WA, Hesdorffer DC, Newton CR, Scorza FA, Sander JW, Tomson T; Epidemiology Commission of the International League Against Epilepsy: The burden of premature mortality of epilepsy in high-income countries: a systematic review from the Mortality Task Force of the International League Against Epilepsy. Epilepsia 2017;58:17-26.

24 Levira F, Thurman DJ, Sander JW, Hauser WA, Hesdorffer DC, Masanja H, Odermatt P, Logroscino G, Newton CR; Epidemiology Commission of the International League Against Epilepsy: Premature mortality of epilepsy in low- and middle-income countries: a systematic review from the Mortality Task Force of the International League Against Epilepsy. Epilepsia 2017;58: 6-16.

25 Logroscino G, Hesdorffer DC, Cascino G, Annegers JF, Hauser WA: Time trends in incidence, mortality, and case-fatality after first episode of status epilepticus. Epilepsia 2001; 42:1031-1035.

26 Sillanpää M, Lastunen S, Helenius H, Schmidt D: Regional differences and secular trends in the incidence of epilepsy in Finland: a nationwide 23-year registry study. Epilepsia 2011; 52:1857-1867.

27 Cockerell OC, Eckle I, Goodridge DM, Sander JW, Shorvon SD: Epilepsy in a population of 6000 re-examined: secular trends in first attendance rates, prevalence, and prognosis. J Neurol Neurosurg Psychiatry 1995;58:570576.

28 GBD 2015 Neurological Disorders Collaborator Group: Global, regional, and national burden of neurological disorders during 19902015: a systematic analysis for the Global Burden of Disease Study 2015. Lancet Neurol 2017; 16:877-897.

29 Keezer MR, Sisodiya SM, Sander JW: Comorbidities of epilepsy: current concepts and future perspectives. Lancet Neurol 2016;15: 106-115.

30 Friedman D, Honig LS, Scarmeas N: Seizures and epilepsy in Alzheimer's disease. CNS Neurosci Ther 2012;18:285-294.

31 Amatniek JC, Hauser WA, DelCastillo-Castaneda C, Jacobs DM, Marder K, Bell K, Albert M, Brandt J, Stern Y: Incidence and predictors of seizures in patients with Alzheimer's disease. Epilepsia 2006;47:867-872.

32 Vossel KA, Beagle AJ, Rabinovici GD, Shu H, Lee SE, Naasan G, Hegde M, Cornes SB, Henry ML, Nelson AB, Seeley WW, Geschwind MD, Gorno-Tempini ML, Shih T, Kirsch HE, Garcia PA, Miller BL, Mucke L: Seizures and epileptiform activity in the early stages of Alzheimer disease. JAMA Neurol 2013;70: 1158-1166.

33 Hesdorffer DC, Hauser WA, Annegers JF, Kokmen E, Rocca WA: Dementia and adultonset unprovoked seizures. Neurology 1996; 46:727-730.

34 Gaitatzis A, Sisodiya SM, Sander JW: The somatic comorbidity of epilepsy: a weighty but often unrecognized burden. Epilepsia 2012; 53:1282-1293.
35 Horváth A, Szücs A, Barcs G, Noebels JL, Kamondi A: Epileptic seizures in Alzheimer disease: a review. Alzheimer Dis Assoc Disord 2016;30:186-192.

36 Vossel KA, Tartaglia MC, Nygaard HB, Zeman AZ, Miller BL: Epileptic activity in Alzheimer's disease: causes and clinical relevance. Lancet Neurol 2017;16:311322 .

37 Camilo O, Goldstein LB: Seizures and epilepsy after ischemic stroke. Stroke 2004;35:17691775.

38 So EL, Annegers JF, Hauser WA, O’Bien PC, Whisnant JP: Population-based study of seizure disorders after cerebral infarction. Neurology 1995;46:350-355.

39 Burn J, Dennis M, Bamford J, Sandercock P, Wade D, Warlow C: Epileptic seizures after a first stroke: the Oxfordshire Community Stroke Project. BMJ 1997;315:1582-1587.

40 Cleary P, Shorvon S, Tallis R: Late-onset seizures as a predictor of subsequent stroke. Lancet 2004;363:1184-1186.

41 Annegers JF, Hauser WA, Elveback LR: Remission of seizures and relapse in patients with epilepsy. Epilepsia 1979;20:729737.

42 Sillanpää M, Schmidt D: Natural history of treated childhood-onset epilepsy: prospective, long-term population-based study. Brain 2006;129:617-624.

43 Bergey GK: Initial treatment of epilepsy: special issues in treating the elderly. Neurology 2004;63(10 suppl 4):S40-S48.

44 Giussani G, Canelli V, Bianchi E, Erba G, Franchi C, Nobili A, Sander JW, Beghi E; EPIRES Group: Long-term prognosis of epilepsy, prognostic patterns and drug resistance: a population-based study. Eur J Neurol 2016;23:1218-1227.

45 Beghi E, Giussani G, Sander JW: The natural history and prognosis of epilepsy. Epileptic Disord 2015;17:243-253.

46 Hesdorffer DC, Benn EK, Cascino GD, Hauser WA: Is a first acute symptomatic seizure epilepsy? Mortality and risk for recurrent seizure. Epilepsia 2009;50:1102-1108. 